\title{
Metabolic Characterization of a Novel ROR $\alpha$ Knockout Mouse Model without Ataxia
}

\author{
Cyrielle Billon, Sadichha Sitaula and Thomas P. Burris* \\ Department of Pharmacology and Physiology, Saint Louis University School of Medicine, St. Louis, MO, United States
}

The retinoic acid receptor-related receptor $\alpha(R O R \alpha)$ is a nuclear receptor that plays an important role in regulation of metabolism and the immune system. Genetic deletion of the receptor yields mice with significant cerebellar developmental issues associated with severe ataxia. Although many metabolic studies have been performed in these models, the impaired locomotor activity of these mice is known to affect their normal mobility and feeding behaviors. This creates some difficulty in interpretation of the role of ROR $\alpha$ in models of metabolic disease where feeding and muscle function is a critical component of the pathophysiology. We generated a mouse with a floxed Rora allele that we crossed

OPEN ACCESS

Edited by:

Paul Webb,

Houston Methodist Research Institute, United States

Reviewed by:

Sana Siddiqui,

University of California, San

Francisco, United States Jonathan Janssens,

University of Antwerp, Belgium

*Correspondence: Thomas P. Burris burristp@s/u.edu

Specialty section: This article was submitted to Molecular and Structural Endocrinology,

a section of the journal

Frontiers in Endocrinology

Received: 16 February 2017 Accepted: 06 June 2017 Published: 11 July 2017

Citation:

Billon C, Sitaula S and Burris TP (2017) Metabolic Characterization of a Novel ROR $\alpha$ Knockout Mouse Model without Ataxia.

Front. Endocrinol. 8:141. doi: 10.3389/fendo.2017.00141 with a mouse line expressing Cre recombinase under the control of the Ella promoter to obtain a full body deletion of Rora. This cross led to a partial deletion of the Rora locus likely due to mosaic expression of the Ella-Cre transgene. These mice lack any signs of ataxia but display an improved metabolic profile relative to normal WT mice. The mice were resistant to diet- and age-induced metabolic syndrome and exhibited improved glucose tolerance and increased insulin sensitivity. Decreased ROR $\alpha$ expression in the mice was also associated with reduced inflammation in models of metabolic syndrome. These data indicate that suppression of ROR $\alpha$ activity improves metabolic function and reduces inflammation.

\section{Keywords: lipids, carbohydrates, nuclear receptor, metabolism, metabolic disease}

\section{INTRODUCTION}

More than two-thirds of American adults are considered to be overweight or obese. Obesity is associated with a range of diseases including diabetes, cardiovascular diseases and several cancers. Obesity is the result of a positive energy balance, a consequence of excess caloric intake relative to calories expended. Energy expenditure is the combination of resting metabolic rate (energy consumed at rest), the thermogenic effect of food (energy utilized to metabolize food consumed), and energy expended during physical activity. When energy expenditure exceeds energy intake, it results in a negative energy balance leading to weight loss. The mechanisms underlying the regulation of energy balance are not completely understood, but evidence suggests that complex physiological regulation and genetic predisposition are involved (1). In addition to behavioral interventions, such as dieting and exercise, various pharmacological strategies are also being examined to reduce obesity focused on reducing caloric intake as well as increasing energy expenditure.

Nuclear receptors (NRs) are ligand-dependent transcription factors that regulate many biological functions including development, metabolism, and inflammation (2). In the context of 
metabolism, NRs control lipid and glucose homeostasis in a tissue-specific manner. Dysfunction of NR signaling has been shown to be associated with dyslipidemia, insulin resistance, diabetes, obesity, and cardiovascular diseases. Retinoic acid receptor-related orphan receptors (RORs) represent a subfamily of the NRs and are involved in regulation of metabolism and inflammation as well as the pathogenesis of atherosclerosis (3-5). The ROR family is composed of three members: ROR $\alpha$, $\operatorname{ROR} \beta$, and ROR $\gamma$. Both $\operatorname{ROR} \alpha$ and $\operatorname{ROR} \gamma$ are expressed in immune cells as well as other tissues known to be the key in regulation of metabolic processes in the liver and skeletal muscle (6). Several studies have implicated ROR $\alpha$ in regulation of glucose and lipid metabolism as well as inflammatory and immune responses in vivo using the staggerer $\left(\mathrm{ROR} \alpha^{\mathrm{sg} / \mathrm{sg}}\right)$ mouse model $(7,8)$. In staggerer mice, the gene encoding $\mathrm{ROR} \alpha$ contains a $6.5 \mathrm{~kb}$ genomic deletion leading to loss of an exon that encodes part of its ligand-binding domain (LBD). This leads to an exon skip that shifts the reading frame and introduces a premature stop codon, providing a truncated protein lacking the entire LBD that is believed to function as a dominant negative protein. Unfortunately, these mice develop severe ataxia (hence the name "staggerer") due to a deficit in Purkinje cell development that impairs mobility and normal feeding behavior, making the study of metabolism more complex in this model. The ROR $\alpha$ null mice display an identical phenotype recapitulating the severe ataxia (9).

In this study, we describe a new mouse model of deletion of $\operatorname{ROR} \alpha$ that does not display ataxia providing an improved model for assessing $\mathrm{ROR} \alpha$-dependent metabolism where "normal" feeding behavior and locomotion are retained. We generated a mouse with a floxed Rora allele that we crossed with a mouse line expressing Cre recombinase under the control of the EIIa promoter to obtain a full body deletion of Rora. As the EIIa-cre model induced a mosaic expression of the cre recombinase, we did not obtain a total recombination of the Rora Flox loci but a partial deletion. These animals (EIIaROR $\alpha \mathrm{KO}$ ) lack any signs of ataxia but display an improved metabolic profile relative to normal $\mathrm{EIIaROR} \alpha \mathrm{WT}$ mice. Our study presents a new model to study the role of $\operatorname{ROR} \alpha$ in metabolic disorders without the complexity of a cerebellar deficit that may alter normal feeding behavior and physical activity. As $\operatorname{ROR} \alpha$ can be targeted by synthetic ligands $(4,10)$, these data suggest that pharmacological modulation of $\operatorname{ROR} \alpha$ may be useful to treat metabolic syndrome and related diseases such as diabetes and liver diseases.

\section{MATERIALS AND METHODS}

\section{Animals}

All procedures were approved and conducted in accordance to the St. Louis University Institutional Animal Care and Use Committee.

All mice were housed in a 12-h light/dark cycle. At the end of the experiment, mice were euthanized by $\mathrm{CO}_{2}$ asphyxiation followed by cervical dislocation. Body composition was analyzed weekly by NMR using BioSpin LF50 Body Composition Analyzer
(Bruker, Germany). Tissues were collected, snap frozen and stored at $-80^{\circ} \mathrm{C}$ for $\mathrm{qPCR}$ or western blotting, or fixed in $4 \%$ formalin, incubated in $20 \%$ sucrose overnight before freezing for cryosection.

\section{Gene Targeting and Generation of Rora Floxed Mice}

The floxed ROR $\alpha$ mouse was created by the transgenics core at the Pennington Biomedical Research Center (Baton Rouge, LA, USA) by inserting LoxP sites by homologous recombination flanking the exon three of the rora gene. Female Rora flox/flox mice were bred with male mice homozygous for the Cre recombinase gene under the control of the adenovirus EIIA promoter to generate the $\mathrm{Rora}^{+} / \Delta \mathrm{Cre} \mathrm{F} 1$ generation. EIIa-Cre transgenic mice were obtained from The Jackson Laboratory (Bar Harbor, ME, USA; stock number: 003724). Genotypes were determined by PCR using the oligonucleotide primers: primer $1: 5^{\prime}$-GCCCCC TTTCCCGCCAGTAGCTG-3'; primer 2: 5'-GACCCAGATCC CCTAATAACG-3'; primer 3:5'-GCCCTCAAGAAGAGGCTGC AATTT-3' (Figure 1A).

\section{Indirect Calorimetry}

Respiratory exchange ratio (RER), $\mathrm{VO}_{2}, \mathrm{VCO}_{2}$, heat production, and activity were measured using a monitoring system (Oxymax Comprehensive Lab Animal System; Columbus Instruments, Columbus, $\mathrm{OH}, \mathrm{USA}$ ). Eight aged-matched male mice (EIIaROR $\alpha$ WT and EIIaROR $\alpha \mathrm{KO}$ ) were housed individually in metabolic cages on a $12 \mathrm{~h}$ day-night cycle, fed with either a normal chow or high fat diet (HFD) (D12492, Research diet). After a 24-h acclimatization period, data were collected every 16 min over a 5 -day period. The hourly or average values during light and dark periods were calculated. Two-way ANOVA followed by Bonferroni posttest was used to calculate the $p$ value.

\section{Glucose and Insulin Tolerance Test (ITT)}

After 6-h fast, EIIaROR $\alpha$ WT and EIIaROR $\alpha \mathrm{KO}(n=8)$ were injected intraperitoneally with glucose $(2 \mathrm{~g} / \mathrm{kg}$ of fat free mass) or insulin $(0.75 \mathrm{U} / \mathrm{kg}$ of fat free mass) (Sigma-Aldrich, St. Louis, MO, USA) to examine glucose tolerance test or ITT, respectively. Blood glucose was measured before the injection $(t=0 \mathrm{~min}), 15,30,60$, and $120 \mathrm{~min}$ after injection using OneTouch Ultra ${ }^{\circledR} 2$ glucometer. Blood was collected by tail snip; the first drop was wiped out, and the second drop was used to quantify glucose level.

\section{Plasma Lipid, Liver Enzyme, and Cytokines Analysis}

Mice were euthanized, and blood was collected via cardiac puncture. Concentration of plasma total cholesterol, high-density lipoprotein (HDL) cholesterol, LDL cholesterol, triglyceride, and liver enzymes were assessed using $\mathrm{Rx}$ Daytona clinical chemistry analyzer (Randox). Plasma TNF $\alpha$ or IL-1 $\beta$ concentrations were detected by ELISA (Mouse TNF alpha ELISA KIT, EMD Millipore and Mouse IL-1 beta Quantikine SixPak, R\&D Systems, respectively) according to the manufacturer's recommendations. 


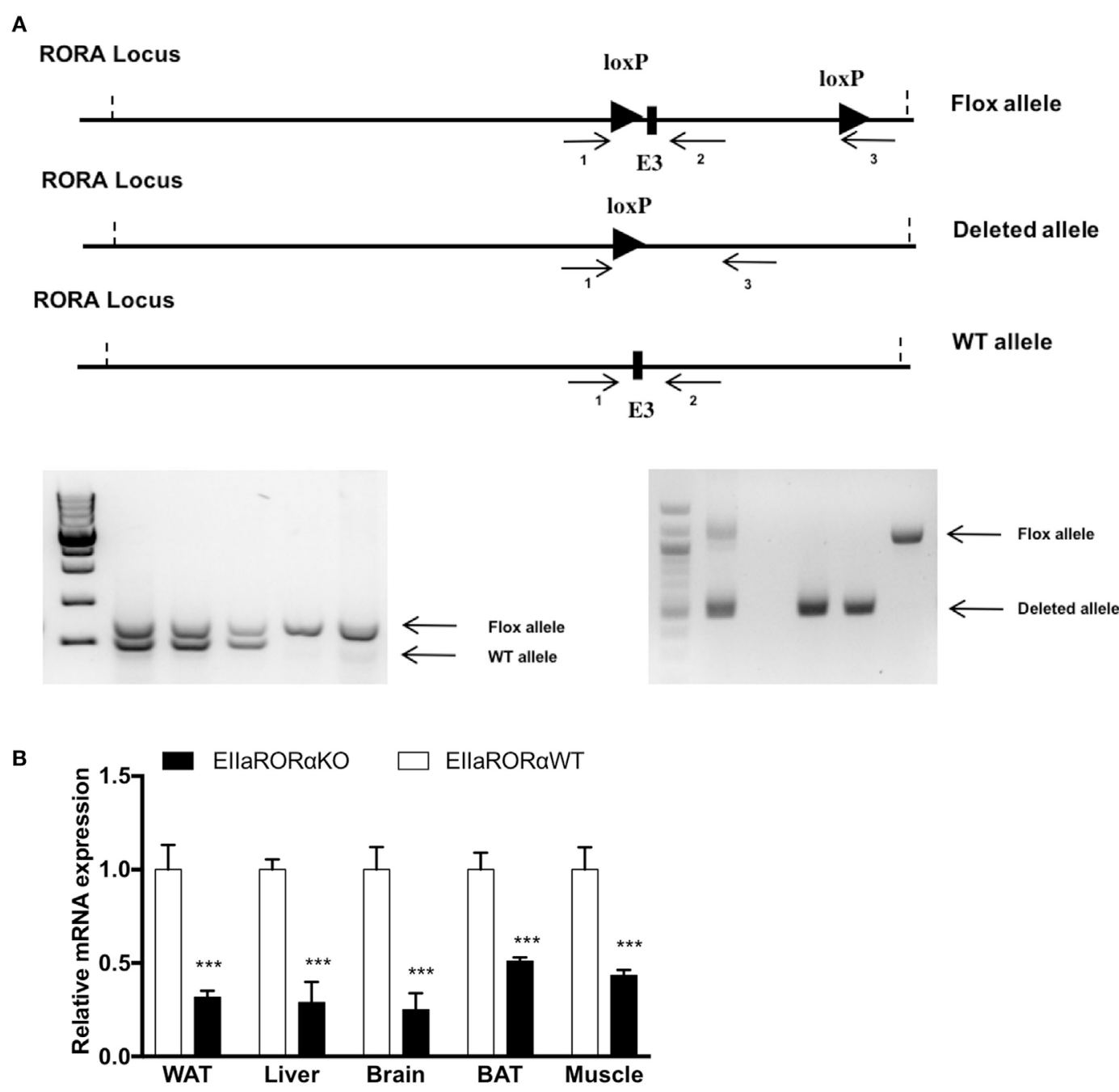

FIGURE 1 | ROR $\alpha$ flox loci construct and validation of ROR $\alpha$ deletion. (A) Schematic representation of the LoxP sequence in ROR $\alpha$ loci and primer localization. To assess the presence of the LoxP sites and the deleted allele after action of the cre recombinase, two sets of primers were designed (1-2 and 1-3). 1.5\%-Agarose gel representing the genotyping results after PCR amplification. The WT and Flox alleles were amplified with the set of primer 1-3, and the deleted allele was amplified with the set of primers 1-3. (B) White adipose tissue (WAT), liver, brain, brown adipose tissue (BAT), and muscle gene expression for ROR $\alpha$ from 2-month-old EIIAROR $\alpha$ WT (white bar, $n=6$ ) and EIIAROR $\alpha$ KO (black bar, $n=6)\left({ }^{* * *} p<0.001\right)$.

\section{Quantitative Real-time PCR}

Total RNA was isolated from mouse tissues using PureLink RNA mini kit (Ambion, Life Technologies). RNA was reverse transcribed to make cDNA using qScript ${ }^{\mathrm{TM}} \mathrm{cDNA}$ Synthesis Kit (Quanta biosciences) according to the manufacturer's instructions. Real-time PCR was performed using a SYBR-green PCR master mix kit (SYBR SELECT MASTER MIX, Life Technologies). Primers were purchased from Integrated DNA Technologies (see Table S1 in Supplementary Material for sequences).

\section{Flow Cytometry}

Spleens and lymph nodes were harvested into a tissue culture dish and teased apart into a single cell suspension. Cell suspension was passed through a cell $0.22 \mu \mathrm{M}$ filter (EMD Millipore) and centrifuged $(300-400 \times g)$ at $4^{\circ} \mathrm{C}$. Cell pellet was resuspended in Flow Cytometry Staining Buffer (BioLegend, San
Diego, CA, USA) at the final concentration of $2 \times 10^{7}$ cells $/ \mathrm{mL}$. Cell surface and intracellular staining were performed according BioLegend protocol (BioLegend). Antibodies used for analysis are listed in Table S2 in Supplementary Material.

\section{Statistical Analysis}

Data are expressed as mean \pm SEM. Student's $t$-test or two-way ANOVA was used to calculate statistical significance. $p<0.05$ was considered significant.

\section{RESULTS}

\section{EllaROR $\alpha$ KO Mice Do Not Display a Staggerer Phenotype}

Previous studies have shown that homozygous staggerer mice are leaner and display improved insulin sensitivity but also have 
a severe cerebellar ataxia (9). To help normalize feeding, these ataxic mice are typically provided food on the bottom of the cage so as to provide more ready access given their locomotor deficits (9). We generated mice heterozygous for a transgene encoding Cre recombinase expressed under the direction of the EIIa promoter (EIIa-Cre), which directs expression in all tissues, and homozygous for loxP-flanked exon 3 of Rora gene [Figure 1A, Rora ${ }^{\text {flox/flox }} \mathrm{Cre}^{+/ \mathrm{WT}}(\mathrm{EIIaROR} \alpha \mathrm{KO})$ ]. Rora Rlox/flox $^{\text {litter- }}$ mates without the EIIa-Cre transgene (EIIaROR $\alpha \mathrm{WT}$ ) served as controls. When we assessed the level of Rora expression in different tissues, we found that the deletion was not complete. Rora expression ranged from 45 to $30 \%$ of normal levels depending on the tissue examined. We observed a significant decrease of expression in several tissues: $65 \%$ in white adipose tissue (WAT), $65 \%$ in liver, $70 \%$ in brain, $55 \%$ in BAT, and $60 \%$ in the skeletal muscle (Figure 1B). The EllaROR $\alpha$ KO mice displayed normal locomotion (Figure S1 in Supplementary Material, activity data at 3-month old) and exhibited no signs of ataxia, from weaning time (day 21) to 15 months of age (data not shown). The residual $\mathrm{ROR} \alpha$ expression in the brain may explain why the EIIaROR $\alpha \mathrm{KO}$ mice do not display ataxia. Overall, no differences in the size or the weight of several organs (liver, kidney, spleen, quadriceps, brown or WATs, heart) were observed (data not shown). There were no gross alterations in brain morphology, but fine characterization of brain morphology and function will be examined in later studies.

\section{EllaROR $\alpha$ KO Mice Preferentially Use Fat for Energy}

Three-month-old male mice (EIIaROR $\alpha \mathrm{KO}$ or EIIaROR $\alpha \mathrm{WT}$ ) were fed with a chow diet and used to decipher the role of ROR $\alpha$ in energy and glucose metabolism. Whole body composition was determined weekly using NMR (BioSpin LF50, Bruker Germany), and no significant differences were observed in body weight, lean mass, or fat mass (Figure 2A). Using indirect calorimetry, we were able to determine that deletion of $\mathrm{ROR} \alpha$ leads to an increase in fat oxidation during both day- and nighttime (Figures 2C,D). No changes in carbohydrate consumption were observed, but we observed an increase in the total quantity of fat oxidized. This increase of fat utilization led to an increase in energy expenditure with neither an increase in food intake nor activity (Figure S1 in Supplementary Material). Typically, an RER of 0.7 indicates that mice are fasted and a difference of 0.05 in the RER reflects a change of $20 \%$ of fuel utilization. Fat oxidation was increased by $20 \%$ in EIIaROR $\alpha$ KO compared to EIIaROR $\alpha$ WT mice when fed a normal chow diet. No differences were observed in levels of blood triglycerides, total cholesterol, HDL, or blood glucose in fasted or fed mice (Figure 2B). ROR $\alpha$ deletion did not alter glucose or insulin tolerance (Figure 2E). Expression of several lipogenic and cholesterologenic enzyme genes in liver was also unaffected by ROR $\alpha$ deletion (Figure 2F). Interestingly, Akt signaling was affected by ROR $\alpha$ deletion. All Akt isoforms (Akt1, 2, and 3) were upregulated in EIIaROR $\alpha$ $\mathrm{KO}$ compared to EIIaROR $\alpha \mathrm{WT}$ mice (Figure 2G). These results demonstrate that $\operatorname{ROR} \alpha$ deletion leads to an increase in fat utilization when mice are fed a normal chow diet, but loss of
ROR $\alpha$ has no effect on glucose utilization or hepatic cholesterol synthesis.

\section{EllaROR $\alpha$ KO Mice Are Resistant to Diet-Induced Obesity (DIO)}

Three-month-old male mice were challenged with an HFD (60\% calories from fat, Harland TD06414) over 14 weeks and monitored for body composition weekly, fuel utilization (at week 1 of HFD) and glucose metabolism. EIIaROR $\alpha \mathrm{KO}$ mice exhibited resistance to DIO displaying significantly reduced body weight gain and reduced fat mass relative to control mice (Figure 3A). After 7 weeks on an HFD, a significant difference in body weight was observed (Figure 3A, left panel) and, surprisingly, after only 2 weeks on an HFD, fat mass was lower in EIIaROR $\alpha \mathrm{KO}$ mice compared to EIIaROR $\alpha \mathrm{WT}$ animals (Figure 3A, right panel). Three-month-old mice were maintained in the metabolic chambers for 2 days on a regular chow diet and then challenged with the same HFD. Metabolic parameters such as RER, oxygen consumption, activity, and energy expenditure were monitored for 5 days. After transition to the HFD, the RER displayed a less pronounced circadian pattern of oscillations (Figure 3B). During both day- and nighttime, the RER of EIIaROR $\alpha$ KO animals was lower than the wild-type counterparts (Figure 3B) consistent with an increase in fatty acid oxidation in the KO mice. We calculated the amount of fatty acid oxidized per hour per kilogram of mouse using the Frayn's equation (11). We observed $13.5 \%$ increase in the quantity of fatty acid oxidized in the EIIaROR $\alpha \mathrm{KO}$ animals compared to control mice (Figure 3C, right panel). No change in carbohydrate oxidation was observed (Figure 3C, left panel). These data suggest that EIIAROR $\alpha \mathrm{KO}$ mice were resistant to DIO due to an increase of fatty acid oxidation even with food intake remaining constant (Figure S1 in Supplementary Material).

\section{HFD-Fed ROR $\alpha$ KO Mice Display Improved Glucose Metabolism and an Anti-inflammatory Profile}

One side effect of obesity is impaired glucose metabolism, which is associated with insulin resistance and type-2 diabetes. We assessed the effect of ROR $\alpha$ deletion in glucose metabolism in HFD-fed mice for 8 weeks. At this time point, a significant difference in body weight and adiposity was observed between EIIAROR $\alpha$ KO mice and their control littermates (Figure 3A). As no differences were observed in lean mass and to avoid an effect due to the body weight, we decided to normalize the amount of glucose or insulin injected to lean mass. No difference in response to glucose (Figure 4A) was observed between the genotypes, but EIIAROR $\alpha \mathrm{KO}$ mice were more sensitive to insulin compared to their EIIAROR $\alpha$ WT littermates (Figure 4B). No differences were observed in fasted blood glucose levels between EIIAROR $\alpha$ KO animals and their control littermates (Figure S2 in Supplementary Material). As obesity is also considered an inflammatory disease, we also assessed the blood levels of pro-inflammatory cytokines IL-1 $\beta$ and TNF $\alpha$. No differences were observed between the two genotypes with respect to circulating IL- $1 \beta$ level, but we found a significant decrease in circulating TNF $\alpha$ levels in EIIAROR $\alpha$ KO 

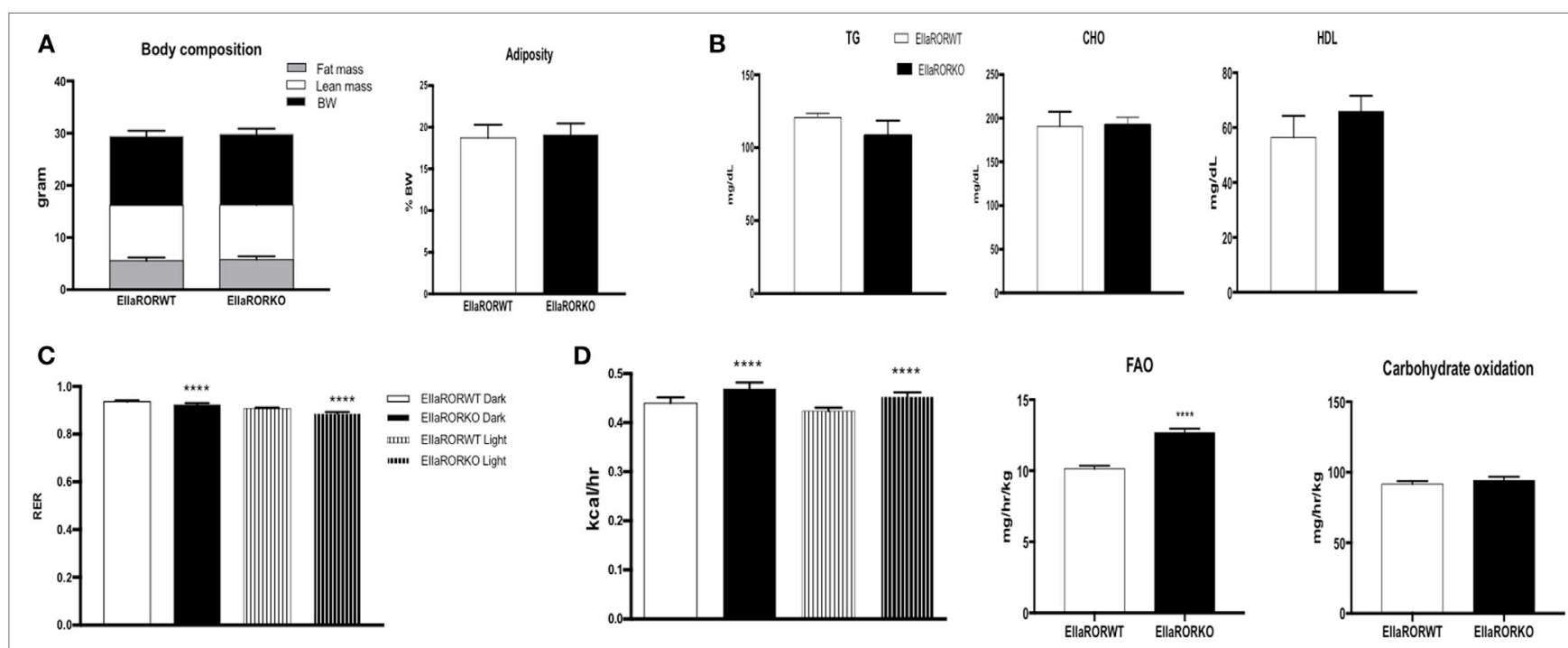

E

GTT

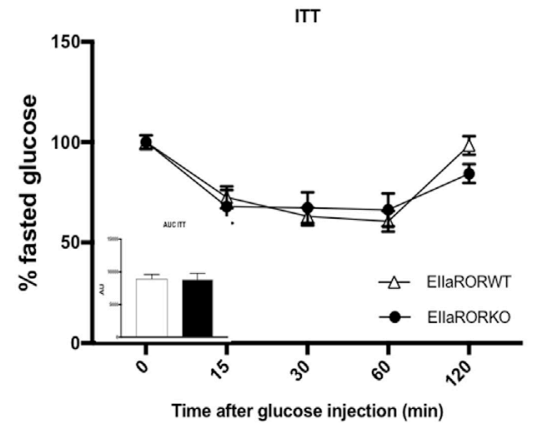

F

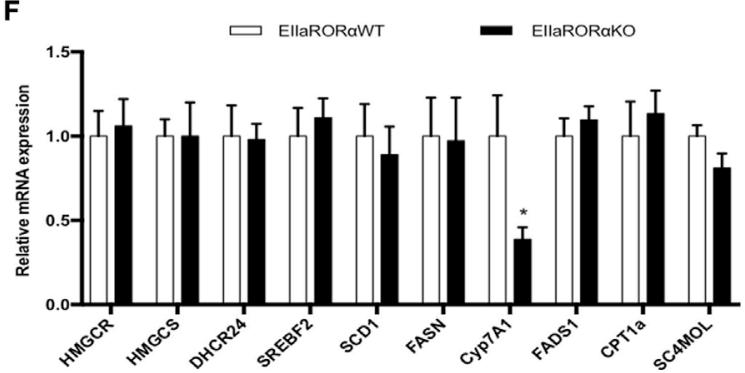

G

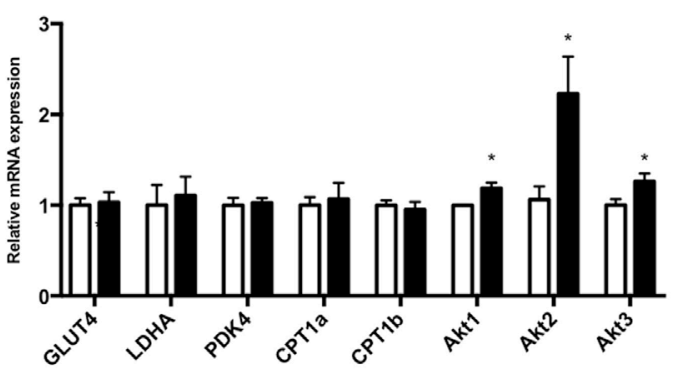

FIGURE 2 | EllAROR $\alpha$ KO mice display an increase fatty acid oxidation and energy expenditure. (A) Body composition of single-housed 12-week-old males ElIAROR $\alpha$ WT $(n=8)$ and ElIAROR $\alpha \mathrm{KO}(n=8)$ littermates (left panel) and adiposity of the same animals (right panel) fed with a normal chow diet. (B) Blood lipid profile (triglycerides, total cholesterol, and HLD) of the same males EllAROR $\alpha$ WT (white bar, $n=8$ ) and EllAROR $\alpha$ KO (black bar, $n=8$ ). (C) Respiration exchange ratio and (D) heat production of the same EIIAROR $\alpha \mathrm{WT}$ (white, $n=8$ ) and EIIAROR $\alpha \mathrm{KO}$ (black, $n=8$ ) littermates during day (solid pattern) or night (shaded pattern) over a 5-day period and after $24 \mathrm{~h}$ acclimation (upper panel). Fatty acid oxidation and carbohydrates consumption of the same males EllAROR $\alpha$ WT (white bar, $n=8$ ) and EllAROR $\alpha$ KO (black bar, $n=8$ ) calculated over a 5-day period. (E) Glucose (left) and insulin (right) tolerance test from the same males EllAROR $\alpha$ WT (white triangle, $n=8$ ) and EllAROR $\alpha \mathrm{KO}$ (black square, $n=8$ ). Area under the curve is represented on each graph. (F) Liver and (G) muscle gene expression from the same males EllAROR $\alpha$ WT (white bar, $n=8)$ and EllAROR $\alpha \mathrm{KO}($ black bar, $n=8)\left({ }^{\star} p<0.05,{ }^{\star \star \star \star} p<0.0001\right)$.

animals compared to EIIAROR $\alpha$ WT mice (Figure 4B; Figure S2 in Supplementary Material). As the WAT can be a source of inflammation, we quantified inflammatory gene expression in this tissue. Most of the pro-inflammatory markers (TNF $\alpha$, IFN $\gamma$, CD36, CD11c) displayed a lower level of expression in EIIAROR $\alpha$ $\mathrm{KO}$ animals compared to EIIAROR $\alpha$ WT mice (Figures 4C,D; Figure S2 in Supplementary Material). T lymphocytes also play a critical role in WAT-associated inflammation and gene expression for FoxP3, a marker for regulatory $\mathrm{T}$ cells $\left(\mathrm{T}_{\mathrm{reg}}\right)$, was increased in EIIAROR $\alpha \mathrm{KO}$ animals compared to EIIAROR $\alpha$ WT suggesting more infiltration of $\mathrm{T}_{\text {reg }}$ cells (Figure S2 in Supplementary Material). Previously, we demonstrated that EIIAROR $\alpha$ KO mice display an anti-inflammatory profile with a decrease in $\mathrm{CD}^{+}$and $\mathrm{CD}^{+}$cell populations in the spleen when fed a chow 


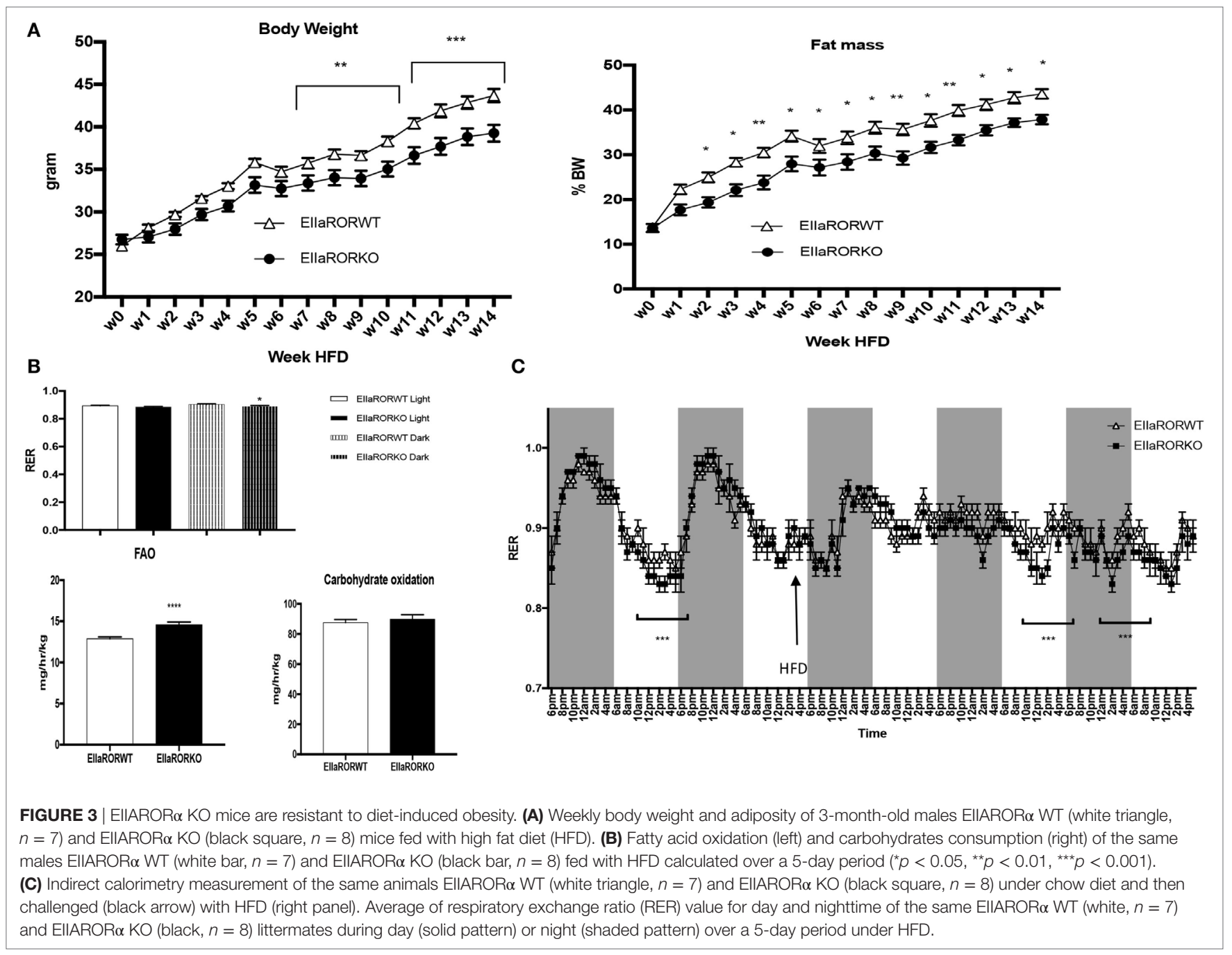

diet (5). These results show that EIIAROR $\alpha \mathrm{KO}$ mice display a lower level of inflammation and improved glucose metabolism relative to EIIAROR $\alpha$ WT mice when they are challenged with an HFD. The expression of several genes encoding lipogenic enzymes was analyzed by qPCR, but no differences were observed between EIIAROR $\alpha$ WT and EIIAROR $\alpha$ KO animals (Figure 4E). Since EIIAROR $\alpha \mathrm{KO}$ mice are more sensitive to insulin, we assessed the role of ROR $\alpha$ deletion in skeletal muscle. The expression of several genes involved in glucose and insulin metabolism was assessed by qPCR, and no major differences were observed between EIIAROR $\alpha \mathrm{WT}$ and EIIAROR $\alpha \mathrm{KO}$ except for Akt expression (Figure 4F).

\section{Aged-EIIAROR $\alpha$ KO Mice Display Improved Glucose Metabolism and an Anti-inflammatory Profile}

Risk for development of metabolic disorders increases with age, thus we decided to study the effect of $\operatorname{ROR} \alpha$ deletion in aging. We used 15-month-old male EIIAROR $\alpha \mathrm{KO}$ and EIIAROR $\alpha$ WT mice maintained on a normal chow diet. No differences in body composition were observed between the two groups (Figure 5A). To determine whether old-EIIAROR $\alpha$ KO mice exhibited increased energy expenditure, we measured activity, heat production, as well as the RER over a 5-day period. No changes were observed in activity, but we observed a decrease in RER suggesting an increase in fat utilization during the resting period (day time) as well as an increase in heat production (Figure 5A). These data suggest that EIIAROR $\alpha \mathrm{KO}$ mice have a higher rate of energy expenditure and fatty acid oxidation. We also observed that old-EIIAROR $\alpha \mathrm{KO}$ mice were more glucose tolerant than old-EIIAROR $\alpha$ WT mice (Figure 5B). When we challenged these mice with insulin, old-EIIAROR $\alpha$ KO mice were more sensitive than the WT mice (Figure 5B). No differences were observed in fasted blood glucose levels (Figure S3 in Supplementary Material). Aging is also associated with increased pro-inflammatory cells and cytokines, thus we studied the proportion of different lymphocytes cell populations in the spleens of these mice by flow cytometry. An increase in anti-inflammatory $\mathrm{T}_{\mathrm{H}} 2$ lymphocytes $\left(\mathrm{CD}^{+} \mathrm{CD}^{+} \mathrm{Gata}^{+}\right)$was observed in old-EIIAROR $\alpha$ KO mice compared to old-EIIAROR $\alpha$ WT mice as well as a decrease of pro-inflammatory lymphocytes 
A

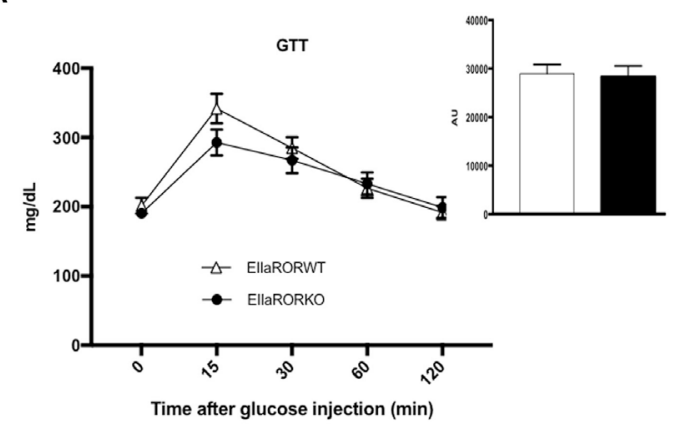

C

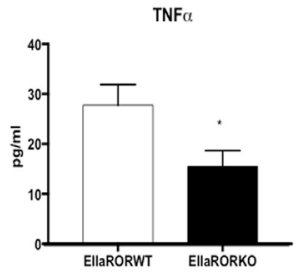

E

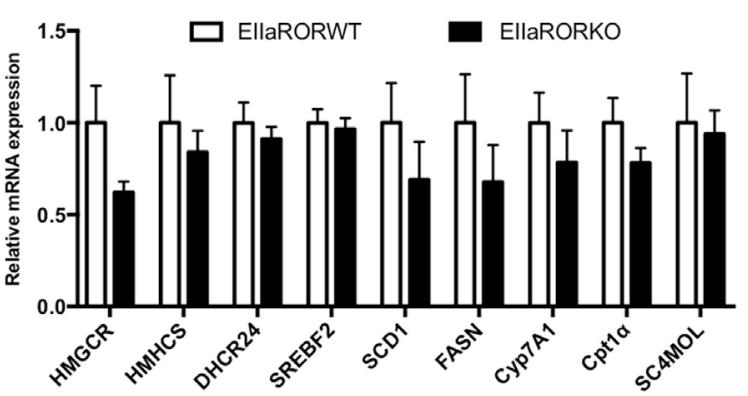

B

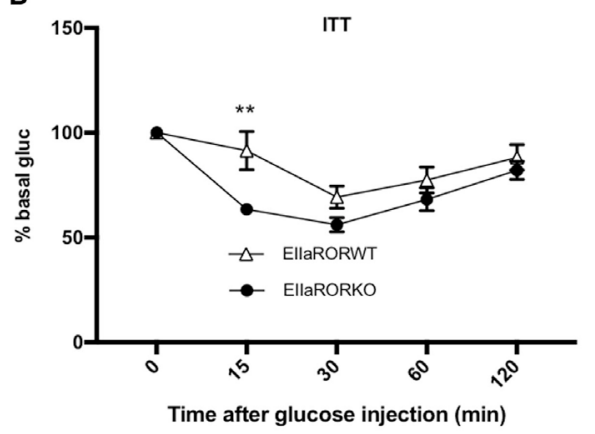

D

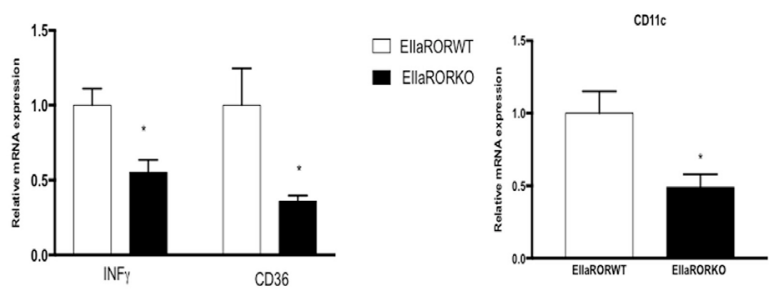

$\mathbf{F}$

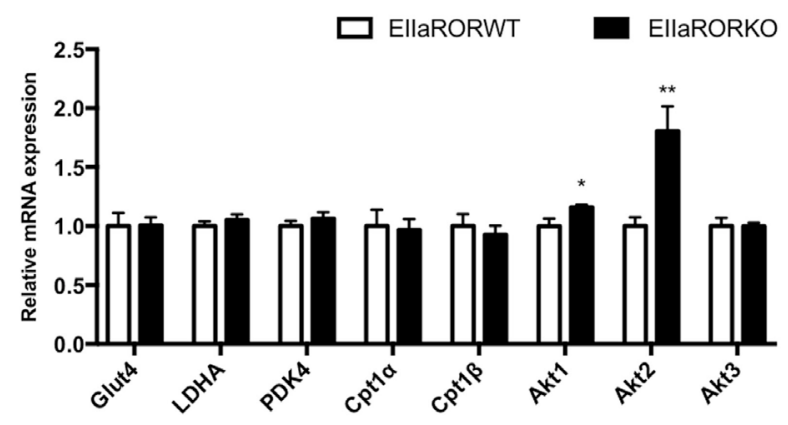

FIGURE 4 | EIIAROR $\alpha$ KO mice fed with high fat diet (HFD) display a better glucose homeostasis than EllAROR $\alpha$ WT mice. (A) Glucose and (B) insulin tolerance test from the same males EIIAROR $\alpha$ WT (white triangle, $n=7$ ) and EllAROR $\alpha$ KO (black square, $n=7$ ) used in the Figure 3, fed with HFD for 8 and 9 weeks, respectively. Area under the curve is represented on each graph. (C) Blood TNF $\alpha$ level of the same males EIIAROR $\alpha$ WT (white triangle, $n=7)$ and EllAROR $\alpha$ KO (black square, $n=7$ ) fed with HFD for 14 weeks quantified by ELISA. (D) WAT gene expression from the same males EllAROR $\alpha$ WT (white triangle, $n=7$ ) and EllAROR $\alpha \mathrm{KO}$ (black square, $n=7$ ) fed with HFD for 14 weeks. (E) Liver and $(\mathbf{F})$ muscle gene expression from the same males EllAROR $\alpha$ WT (white bar, $n=7$ ) and EIIAROR $\alpha \mathrm{KO}$ (black bar, $n=7)\left({ }^{*} p<0.05,{ }^{* *} p<0.01\right)$.

$\mathrm{T}_{\mathrm{H}} 17\left(\mathrm{CD}^{+} \mathrm{CD}^{+} \mathrm{IL}-17^{+}\right.$; Figure $\left.5 \mathrm{C}\right)$. No changes were observed in number of $\mathrm{T}_{\mathrm{H}} 1$ lymphocytes or $\mathrm{T}_{\text {reg }}$ lymphocytes between the genotypes (Figure S3 in Supplementary Material). In WAT, a decrease in TNF $\alpha$ expression and an increase the expression of anti-inflammatory genes such as TGF $\beta$ and macrophage infiltration marker CD36 were observed in old-EIIAROR $\alpha$ KO mice compared to old-EIIAROR $\alpha$ WT mice (Figure 5D). These results suggest that deletion of $\mathrm{ROR} \alpha$ can be protective in ageinduced metabolic disorders such as diabetes and obesity.

\section{DISCUSSION}

In this study, we have described a novel mouse model that we used to characterize the role of $\operatorname{ROR} \alpha$ in metabolic disorders. These EIIAROR $\alpha$ KO mice, which expressed significantly reduced
ROR $\alpha$ expression relative to WT mice but did not display mobility/ataxia issues typically associated with loss of ROR $\alpha$ function, were protected against diet- and age-induced metabolic syndrome. In these mice, reduction of $\mathrm{ROR} \alpha$ expression protected against DIO and improved glucose metabolism and insulin resistance were observed while also decreasing markers of inflammation. Our study extends previous ones utilizing the staggerer mouse model that also suggest a metabolic benefic of ROR $\alpha$ deletion $(7,8)$. However, metabolic studies in the staggerer mouse have typically been difficult to interpret due to significant developmental abnormalities in these mice leading to cerebellar ataxia. Interestingly, our new mouse model that exhibits a partial deletion of ROR $\alpha$ lacks the troublesome ataxia that leads to abnormal movement and feeding, but we were still able to clearly link lower $\mathrm{ROR} \alpha$ activity to improved glucose metabolism, reduced insulin 


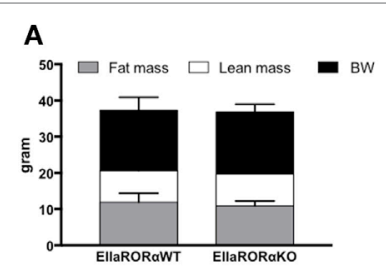

B
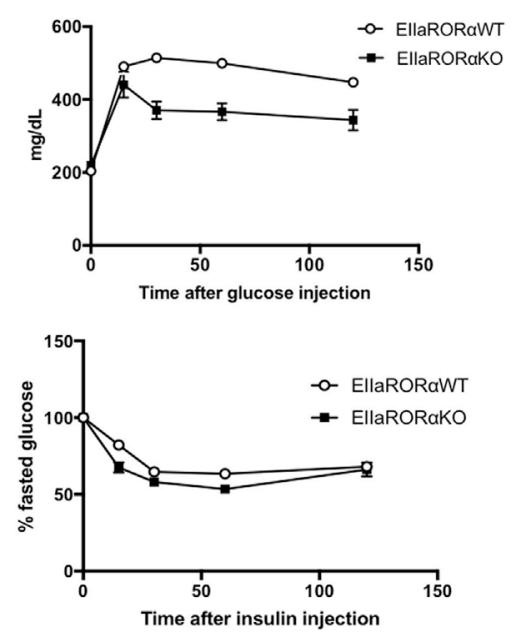

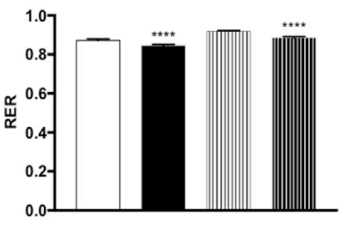

GT
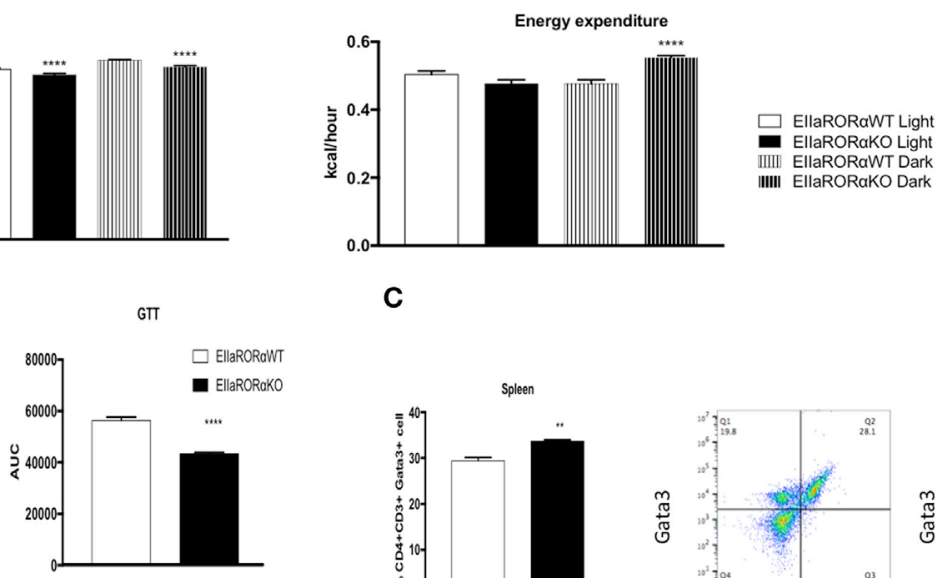
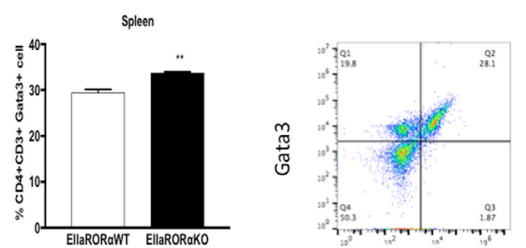

CD4

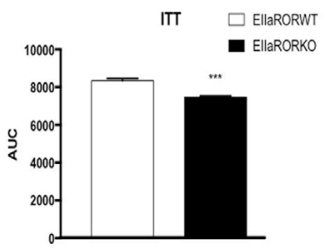

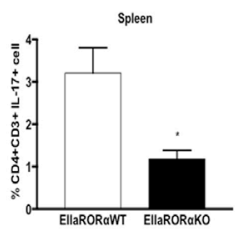

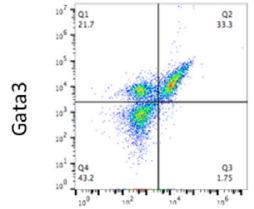

CD4

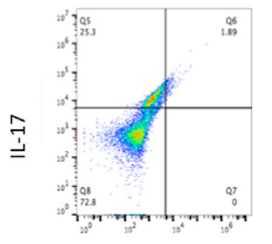

$\mathrm{CD} 4$

D

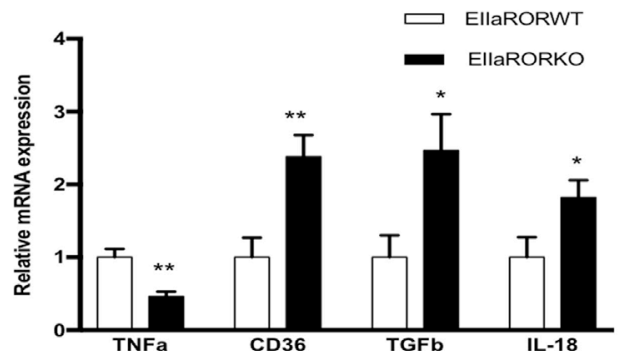

FIGURE 5 | Aged-EllAROR $\alpha$ KO display improved glucose homeostasis and a lower inflammation rate than EllAROR $\alpha$ WT mice. (A) Body composition of single-housed 15-month-old males ElIAROR $\alpha \mathrm{WT}(n=6)$ and ElIAROR $\alpha \mathrm{KO}(n=7)$ littermates (left panel) fed with a normal chow diet. Respiration exchange ratio (middle panel) and heat production (right panel) of the same aged-EllAROR $\alpha$ WT (white, $n=6$ ) and EllAROR $\alpha \mathrm{KO}$ (black, $n=7$ ) littermates during day (solid pattern) or night (shaded pattern) over a 5-day period and after $24 \mathrm{~h}$ acclimation (upper panel). (B) Glucose (upper panel) and insulin (lower panel) tolerance test from the same males aged-EIIAROR $\alpha$ WT (white triangle, $n=6$ ) and EIIAROR $\alpha \mathrm{KO}$ (black square, $n=7$ ) fed with a normal chow diet done at $13-\mathrm{month}$ old. Area under the curve is represented on each graph. (C) Splenocytes from 15-month-old males EllAROR $\alpha$ WT (white bar, $n=6$ ) and EllAROR $\alpha$ KO (black bar, $n=7$ ) littermates were analyzed by flow cytometry for $\mathrm{T}_{\mathrm{H}} 2\left[\mathrm{CD} 3^{+} \mathrm{CD} 4^{+} \mathrm{Gata3}^{+}\right.$(upper panel)], or $\mathrm{T}_{\mathrm{H}} 17$ [CD3+CD4+IL-17+ (lower panel)]. (D) WAT gene expression from the same 15-monthold males EllAROR $\alpha$ WT (white bar, $n=6$ ) and EllAROR $\alpha$ KO (black bar, $n=7)$ littermates $\left({ }^{\star} p<0.05,{ }^{* *} p<0.01,{ }^{* \star *} p<0.001,{ }^{* \star \star *} p<0.0001\right)$.

resistance, resistance to diet- or age-induced obesity, and reduced inflammation. These mice also display increased energy expenditure and increased fatty acid oxidation and a reduction in fat mass when maintained on a normal chow diet or an HF diet. Obesity is associated with mild systemic inflammation and that inflammation plays a critical role in pathologies associated to obesity like cardiovascular diseases as well as diabetes. Our study has shown a correlation between level of expression of ROR $\alpha$, inflammation, and resistance to diet- and age-induced obesity. Infiltration of immune cells, macrophages and T lymphocytes, in WAT leads to production of systemic pro-inflammatory cytokine that trigger the development of systemic inflammation found in obese patients or animal models (12-14). RORs (ROR $\alpha$ and $\operatorname{ROR} \gamma)$ are known to play a role in atherosclerosis and lymphocytes $T_{H} 17$ differentiation $(4,5)$. Our data have shown that a partial deletion of $\operatorname{ROR} \alpha$ is sufficient to reduce inflammation and induce $\mathrm{T}_{\text {reg }}$ differentiation and/or proliferation to prevent an increase in inflammation in the WAT. The spleen plays a major role in $\mathrm{T}$ cell maturation and activation, and our cytometry study shows an anti-inflammatory profile of T cells in aged-EIIAROR $\alpha$ KO mice. Previously, we showed a similar profile in young EIIAROR $\alpha$ KO mice under chow diet (5). All these data support the proinflammatory role of $\mathrm{ROR} \alpha$, and modulation of its activity can protect against pathological inflammation. One of the key factors controlling $\mathrm{T}$ cell fate is the transcription factor hypoxiainducible factor- $1 \alpha$ (HIF-1 $\alpha)$. HIF- $1 \alpha$ is activated by the level of 
oxygen and can be regulated by the NF- $\mathrm{KB}$ signaling pathway in T cells. Activation of HIF- $1 \alpha$ will induced a metabolic switch in cells, which dramatically influences $\mathrm{T}$ cell lineage commitment (15). HIF- $1 \alpha$ can attenuate $\mathrm{T}_{\text {reg }}$ differentiation toward $\mathrm{T}_{\mathrm{H}} 17$. Interestingly, HIF- $1 \alpha$ has been shown to by directly regulated by $\operatorname{ROR} \alpha(16)$. We hypothesized that the deletion of ROR $\alpha$ can lead to a decrease of HIF- $1 \alpha$ expression in naive T cells $\left(\mathrm{CD} 4^{+}\right)$that will promote $\mathrm{T}_{\text {reg }}$ differentiation and block $\mathrm{T}_{\mathrm{H}} 17$ differentiation.

Aged-EIIAROR $\alpha \mathrm{KO}$ or EIIAROR $\alpha \mathrm{KO}$ mice under $\mathrm{HF}$ diet for weeks are still insulin sensitive and glucose tolerant, suggesting that these mice are less susceptible to aged or diet-induced type-2 diabetes. Very interestingly, we observed an upregulation of Akt signaling in the muscle of EIIAROR $\alpha \mathrm{KO}$ animals, which could explain the more efficient insulin signaling. Further studies regarding the insulin pathway will be necessary to understand the role of ROR $\alpha$ deletion in this process. The mechanisms underlying these results are not clear, but it could be a link to a decrease of inflammation and a better peripheral glucose metabolism. The muscles play a critical role in glucose metabolism and insulin sensitivity (17). Previous data obtained in the lab have shown that targeting ROR $\alpha$ and ROR $\gamma$ with synthetic inverse agonist reduces diabetes in a non-obese mouse model (18). The role of each ROR isotype is poorly understood in these mechanisms. Our model will allow us to also study the role of ROR $\alpha$ in specific tissues such as muscle and pancreas and its impact in glucose metabolism and insulin sensitivity.

Obesity and fat accumulation are the results of imbalance between energy intake and expenditure. Indirect calorimetry analysis of 2-month-old EIIAROR $\alpha \mathrm{KO}$ and EIIAROR $\alpha$ WT fed with normal chow diet as well as aged EIIAROR $\alpha \mathrm{KO}$ and EIIAROR $\alpha$ WT have shown an increase in energy expenditure and fatty acid oxidation without alteration of food intake during both night- and daytime. We hypothesized that the increase in energy expenditure was linked to an increase in thermogenesis in the brown adipose tissue (BAT). To test this, we challenged young EIIAROR $\alpha \mathrm{KO}$ and EIIAROR $\alpha \mathrm{WT}$ to cold temperature, but no differences were observed in energy expenditure, fatty acid oxidation, or BAT activity (data not shown). We then challenged EIIAROR $\alpha \mathrm{KO}$ and EIIAROR $\alpha$ WT mice with $\mathrm{HF}$ diet for 8 weeks before performing the same indirect calorimetry analysis. As EIIAROR $\alpha \mathrm{KO}$ mice accumulate less fat, the normalization to the fat free mass excludes any weight effect in energy expenditure. EIIAROR $\alpha \mathrm{KO}$ mice are utilizing more energy during both day- and nighttime and have an increase in fatty acid oxidation. Fatty acid oxidation has been shown to be impaired in aging animals (19), but our aged-EIIAROR $\alpha$ KO still display an increase in fatty acid oxidation. These results lead to the hypothesis that $\mathrm{ROR} \alpha$ may regulate fatty acid oxidation and prevent against aged-dependent decrease of metabolism. The elevated energy expenditure and fatty acid oxidation observed in all our models might explain the reduced fat accumulation and insulin resistance in EIIAROR $\alpha \mathrm{KO}$ mice.

In conclusion, we developed a new $\mathrm{ROR} \alpha$ deficiency mouse model that recapitulates the observations performed in the Staggerer mice but without the problematic effects of ataxia. Partial deletion of $\operatorname{ROR} \alpha$ protects against diet- and age-induced metabolic syndromes and inflammation. This ROR $\alpha$ floxed model will provide a new tool to study the role of $\mathrm{ROR} \alpha$ in metabolic syndrome. By generating tissue-specific ROR $\alpha$ deletions using this model, we will be able to better understand the role of ROR $\alpha$ in metabolic tissue and some of the problematic cerebellar developmental effects. We previously published that ROR can be targeted by synthetic ligands and protects against inflammation, diabetes, and cardiovascular diseases $(4,5,18)$, but unfortunately, we have not been able to decipher the specific role of each receptor isotype nor the role of various isotypes within specific tissues with great precision. With this model, we will be able to better understand the role of ROR $\alpha$ versus ROR $\gamma$ in these diseases and utilize this information to develop improved therapeutic strategies to manage and prevent obesity and related pathologies such as cardiovascular diseases and diabetes.

\section{ETHICS STATEMENT}

All animal studies were approved by the SLU IACUC.

\section{AUTHOR CONTRIBUTIONS}

$\mathrm{TB}$ and $\mathrm{CB}$ conceptualized the project; wrote and edited the paper. CB and SS performed experiments. All the authors analyzed the data.

\section{ACKNOWLEDGMENTS}

This work was supported by the National Institutes of Health (MH092769). The authors thank Dr. Fernanda Ruiz for her critical reading of the manuscript.

\section{SUPPLEMENTARY MATERIAL}

The Supplementary Material for this article can be found online at http://journal.frontiersin.org/article/10.3389/fendo.2017.00141/ full\#supplementary-material.

FIGURE S1 | Food intake and activity of single-housed ElIAROR $\alpha$ WT and ElIAROR $\alpha$ KO mice. (A) Food intake of single-housed 12-week-old males EIIAROR $\alpha$ WT (white bar, $n=8$ ) and EllAROR $\alpha \mathrm{KO}$ (black bar, $n=8$ ) littermates under chow diet over a month. (B) Recording of single-housed 12-week-old males EIIAROR $\alpha$ WT (white triangle, $n=8$ ) and EIIAROR $\alpha$ KO (black square, $n=8$ ) littermate activity in metabolic chambers over a 4-day period. Dark shaded represents nighttime. (C) Average of daily food intake of single-housed males EIIAROR $\alpha$ WT (white bar, $n=7$ ) and EIIAROR $\alpha \mathrm{KO}$ (black bar, $n=7$ ) littermates under high fat diet over 14-week period.

FIGURE S2 | Blood glucose and inflammatory parameters in male EllAROR $\alpha$ WT and EIIAROR $\alpha \mathrm{KO}$ mice under chow diet. (A) Fasted blood glucose level from males EIIAROR $\alpha$ WT (white bar, $n=7$ ) and ElIAROR $\alpha \mathrm{KO}$ (black bar, $n=7$ ) after 10 weeks of high fat diet (HFD). (B) Blood IL-1b level in the males EllAROR $\alpha$ WT (white bar, $n=7$ ) and EllAROR $\alpha \mathrm{KO}$ (black bar, $n=7$ ) after 14 weeks of HFD determined by ELISA. (C) WAT gene expression from males EIIAROR $\alpha$ WT (white bar, $n=7$ ) and EIIAROR $\alpha$ KO (black bar, $n=7$ ) after 14 weeks of HFD $\left({ }^{*} p<0.05\right)$.

FIGURE S3 | (A) Fasted blood glucose level from 13-month-old EllAROR $\alpha$ WT males (white bar, $n=6$ ) and EIIAROR $\alpha \mathrm{KO}$ (black bar, $n=7$ ) mice fed with normal chow diet. (B) Splenocytes from 15-month-old males ElIAROR $\alpha$ WT (white bar, $n=6$ ) and EllAROR $\alpha \mathrm{KO}$ (black bar, $n=7$ ) littermates were analyzed by flow cytometry for $\mathrm{Th} 1\left[\mathrm{CD} 3^{+} \mathrm{CD} 4+\mathrm{IFN} \gamma^{+}\right.$(left panel)], or regulatory $\mathrm{T}$ cells $\left(\mathrm{T}_{\text {reg }}\right)$ $\left[\mathrm{CD}^{+}{ }^{+} \mathrm{CD} 4{ }^{+}{ }^{+}\right.$oxP3 $3^{+}$(right panel)] $\left({ }^{\star} p<0.05,{ }^{\star \star} p<0.01,{ }^{* \star *} p<0.001\right)$. 


\section{REFERENCES}

1. Hill J, Wyatt H. The myth of healthy obesity. Ann Intern Med (2013) 159:789-90. doi:10.7326/0003-4819-159-11-201312030-00016

2. Beaven S, Tontonoz P. Nuclear receptors in lipid metabolism: targeting the heart of dyslipidemia. Annu Rev Med (2006) 57:313-29. doi:10.1146/annurev. med.57.121304.131428

3. Giguère V, Tini M, Flock G, Ong E, Evans RM, Otulakowski G. Isoformspecific amino-terminal domains dictate DNA-binding properties of ROR alpha, a novel family of orphan hormone nuclear receptors. Genes Dev (1994) 8:538-53. doi:10.1101/gad.8.5.538

4. Solt LA, Kumar N, Nuhant P, Wang Y, Lauer JL, Liu J, et al. Suppression of TH17 differentiation and autoimmunity by a synthetic ROR ligand. Nature (2011) 472:491-4. doi:10.1038/nature10075

5. Billon C, Sitaula S, Burris T. Inhibition of ROR $\alpha / \gamma$ suppresses atherosclerosis via inhibition of both cholesterol absorption and inflammation. Mol Metab (2016) 5:997-1005. doi:10.1016/j.molmet.2016.07.001

6. Kang HS, Angers M, Beak JY, Wu X, Gimble JM, Wada T, et al. Gene expression profiling reveals a regulatory role for ROR alpha and ROR gamma in phase I and phase II metabolism. Physiol Genomics (2007) 31:281-94. doi:10.1152/ physiolgenomics.00098.2007

7. Kang HS, Okamoto K, Takeda Y, Beak JY, Gerrish K, Bortner CD, et al. Transcriptional profiling reveals a role for RORalpha in regulating gene expression in obesity-associated inflammation and hepatic steatosis. Physiol Genomics (2011) 43:818-28. doi:10.1152/physiolgenomics.00206.2010

8. Lau P, Fitzsimmons RL, Pearen MA, Watt MJ, Muscat GE. Homozygous staggerer $(\mathrm{sg} / \mathrm{sg})$ mice display improved insulin sensitivity and enhanced glucose uptake in skeletal muscle. Diabetologia (2011) 54:1169-80. doi:10.1007/ s00125-011-2046-3

9. Dussault I, Fawcett D, Matthyssen A, Bader J-A, Giguère V. Orphan nuclear receptor ROR $\alpha$-deficient mice display the cerebellar defects of staggerer. Mech Dev (1998) 70:147-53. doi:10.1016/S0925-4773(97)00187-1

10. Kumar N, Lyda B, Chang MR, Lauer JL, Solt LA, Burris TP, et al. Identification of SR2211: a potent synthetic ROR $\gamma$ selective modulator. ACS Chem Biol (2012) 7:672-7. doi:10.1021/cb200496y

11. Frayn K. Calculation of substrate oxidation rates in vivo from gaseous exchange. J Appl Physiol Respir Environ Exerc Physiol (1983) 55:628-34.
12. Feuerer M, Herrero L, Cipolletta D, Naaz A, Wong J, Nayer A, et al. Lean, but not obese, fat is enriched for a unique population of regulatory $\mathrm{T}$ cells that affect metabolic parameters. Nat Med (2009) 15:930-9. doi:10.1038/ nm. 2002

13. Bastard JP, Maachi M, Lagathu C, Kim MJ, Caron M, Vidal H, et al. Recent advances in the relationship between obesity, inflammation, and insulin resistance. Eur Cytokine Netw (2006) 17:4-12.

14. McArdle M, Finucane O, Connaughton R, McMorrow A, Roche H. Mechanisms of obesity-induced inflammation and insulin resistance: insights into the emerging role of nutritional strategies. Front Endocrinol (2013) 4:52. doi:10.3389/fendo.2013.00052

15. Dang EV, Barbi J, Yang HY, Jinasena D, Yu H, Zheng Y, et al. Control of $\mathrm{T}(\mathrm{H}) 17 / \mathrm{T}(\mathrm{reg})$ balance by hypoxia-inducible factor 1. Cell (2011) 146:772-84. doi:10.1016/j.cell.2011.07.033

16. Kim EJ, Yoo YG, Yang WK, Lim YS, Na TY, Lee IK, et al. Transcriptional activation of HIF-1 by RORalpha and its role in hypoxia signaling. Arterioscler Thromb Vasc Biol (2008) 28:1796-802. doi:10.1161/ATVBAHA.108.171546

17. Sinacore D, Gulve E. The role of skeletal muscle in glucose transport, glucose homeostasis, and insulin resistance: implications for physical therapy. Phys Ther (1993) 73:878-91. doi:10.1093/ptj/73.12.878

18. Solt L, Banerjee S, Campbell S, Kamenecka T, Burris T. ROR inverse agonist suppresses insulitis and prevents hyperglycemia in a mouse model of type 1 diabetes. Endocrinology (2015) 156:869-81. doi:10.1210/en.2014-1677

19. Tucker M, Turcotte L. Impaired fatty acid oxidation in muscle of aging rats perfused under basal conditions. Am J Physiol Endocrinol Metab (2002) 282:E1102-9. doi:10.1152/ajpendo.00175.2001

Conflict of Interest Statement: The authors declare that the research was conducted in the absence of any commercial or financial relationships that could be construed as a potential conflict of interest.

Copyright $\odot 2017$ Billon, Sitaula and Burris. This is an open-access article distributed under the terms of the Creative Commons Attribution License (CC BY). The use, distribution or reproduction in other forums is permitted, provided the original author(s) or licensor are credited and that the original publication in this journal is cited, in accordance with accepted academic practice. No use, distribution or reproduction is permitted which does not comply with these terms. 